\title{
The Significance of Height on Median and Ulnar Nerves Conduction Parameters in Male Subjects
}

\author{
Nawrass Jassim ${ }^{1 *}$ (D) Hayder Abdulateef ${ }^{2}$ (D) Khalida I. Noel ${ }^{2} \mathbb{D}$ \\ ${ }^{1}$ Department of Physiology, PHD Neurophysiology, College of Medicine, University of Babylon, Hillah, Iraq; ${ }^{2}$ Department of \\ Human Anatomy, College of Medicine, Al-Mustansiriyah University, Baghdad, Iraq
}

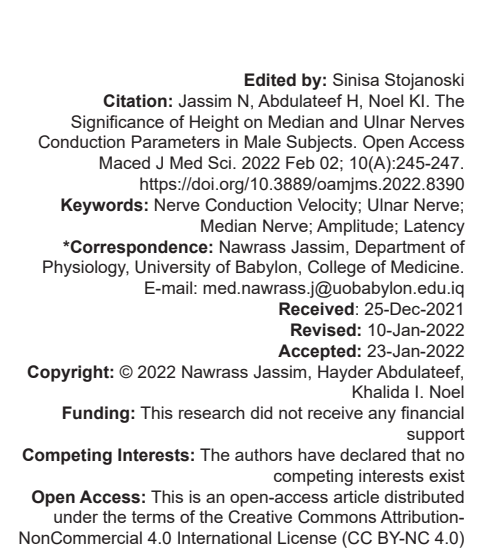

\section{Introduction}

The studies of nerve conduction are tests that used to evaluate the function of both sensory and motor nerves and their capability to conduct the electrical impulses, it considered an important tool to diagnose the disease and monitor its progression and plays an important role in assessing the complications of the treatment and usually are safe and tolerable [1]. Commonly measured parameters for motor nerves contain latency, amplitude, duration, conduction velocity, and late response like F-waves, while for sensory nerves, the parameters are amplitude, latency, period, and transmission speed only. These parameters are well-known to vary with anthropometric measurements of the population studied and laboratory conditions of the test [2]. Many physiological factors such as age, height, gender, and temperature are known to influence the nerve conduction parameters. False results may obtained in case of ignoring these physiological factors, so to obtain real evaluation for nerve transmission studies and later on the diagnosis of the diseases, we need authoritarian control of temperature with quantity the anthropometric variables [3]. Many studies conducted to evaluate the correlation between this anthropometric factors and the nerve conduction parameters, some have been found that there is no distinction in nerve conduction study between males and females [4], [5], other revisions concerning height and nerve conduction velocity had controversy results [6]. Several studies were conducted to evaluate the effect of anthropometric data such as age, gender, BMI, and height on sensory and motor nerve conduction parameters in many other countries, in this study, we evaluate the effect of height on the median and ulnar nerve conduction (sensory and motor) parameters in only male subjects in our Iraqi population.

\section{Materials and Methods}

This cross-sectional study was carried out during the period of December 2019 to June 2021. It consists of 70 male, their age ranging between 18 and 65 years and their height ranges between 165 and $187 \mathrm{~cm}$. The female not included in this study to excluded the effects of gender on the results. For all those subjects, related history was taken regarding age, height, and medical history of diseases with 
clinical examination, then after, the procedure of nerve conduction was explained and oral consent was obtained. Any subject had diabetes, hypertension, thyroid or liver diseases, smoking, any cervical or lumbosacral surgery, entrapment syndrome, and any extra illness that may disturb nerve conduction such as nerve injury; neuropathy, neuromuscular disorders, and myopathic diseases were expelled from the study. By using four channels NEHON KHODIN machine, the sensory and motor fibers of both median and ulnar nerves were tested and the room temperature was kept at $26 \pm 2{ }^{\circ} \mathrm{C}$.

Table 1: Authority of height on median and ulnar nerve motor latency, amplitude, and conduction velocity

\begin{tabular}{lllllll}
\hline Parameter & Nerve & & Regression & $\mathrm{p}$ value & Odd's & $95 \% \mathrm{Cl}$ \\
\hline Height & Median & Latency $(\mathrm{ms})$ & 0.14 & 0.235 & 1.13 & $-2.22-6.47$ \\
& & Amplitude $(\mathrm{mV})$ & 0.08 & 0.494 & 1.09 & $-0.39-0.90$ \\
& & Conduction velocity $(\mathrm{m} / \mathrm{s})$ & -0.10 & 0.393 & 0.92 & $-0.57-0.30$ \\
& \multirow{2}{*}{ Innar } & Latency $(\mathrm{ms})$ & 0.02 & 0.835 & 1.00 & $-4.12-4.25$ \\
& & Amplitude $(\mathrm{mV})$ & 0.03 & 0.788 & 1.01 & $-0.80-0.93$ \\
& & Conduction velocity $(\mathrm{m} / \mathrm{s})$ & -0.10 & 0.368 & 0.89 & $-0.40-0.16$ \\
\hline
\end{tabular}

For sensory study, both median and ulnar nerves were assessed antidromically, especial ring electrodes were used with application of adequate mount of gel to ensure good contact between the electrodes and the skin. For sensory median nerve assessment, two ring electrodes were used, one of them is active electrodes (G1) and the other one is reference electrode (G2) put on the second or index finger of the subject and adequate stimulation was applied on the wrist about $14 \mathrm{~cm}$ proximal to $\mathrm{G} 1$ medial to the flexor carpi radialis tendon (1) to get the maximum sensory amplitude (SNAP), and for ulnar nerve the ring electrodes (G1 and G2) put on the fifth finger with adequate stimulation applied on the wrist nearly $10 \mathrm{~cm}$ proximal to $\mathrm{G} 1$ (1) next to the flexor carpi ulnaris tendon then after, the complete nerve parameters were analyzed (latency, amplitude, and conduction velocity) (1). Regarding the motor conduction study, the G1 located over the bellied of abductor policies brevis for the median nerve and over the abductor digiti minimi for the ulnar nerve. The reference electrode (G2) was positioned $3 \mathrm{~cm}$ distally over the first metacarpo-phalangeal joint for the median nerve and over the fifth metacarpo-phalangeal joint for the ulnar nerve. The spots of prompt for the two nerves were at wrist and elbow area (1). The parameters that measured for both median and ulnar nerves were:

1. Latency in milliseconds (ms).

2. Amplitude in millivolt $(\mathrm{mV})$ for motor fibers and microvolt $(\mu \mathrm{V})$ for sensory fibers.

3. Conduction velocity in meters per second $(\mathrm{m} / \mathrm{s})$.

\section{Statistical analysis}

Statystical analysis was done by SPSS version 21. Correlation between heights with the nerve conduction study variables was done by Pearson's correlation. A significant difference reflected at $p<0.05$.

\section{Results}

Through this cross-sectional study, 70 healthy male subjects were included, their ages were ranged between 18 and 60 years (mean $\pm S D=35.0 \pm 10.7$ years) and their height was ranging between 160 and $185 \mathrm{~cm}$ (mean $\pm S D=173.3 \pm 6.4 \mathrm{~cm}$ ). The power of height on motor and sensory conduction parameters of both median and ulnar nerves is shown in Tables 1 and 2 , respectively.

Table 2: Power of height on median and ulnar nerve sensory latency, amplitude, and conduction velocity

\begin{tabular}{|c|c|c|c|c|c|c|}
\hline \multirow{2}{*}{$\begin{array}{l}\text { Parameter } \\
\text { Height }(\mathrm{cm})\end{array}$} & \multicolumn{2}{|l|}{ Nerve } & \multirow{2}{*}{$\begin{array}{l}\text { Regression } \\
0.22\end{array}$} & \multirow{2}{*}{$\begin{array}{l}p \text { value } \\
0.06\end{array}$} & \multirow{2}{*}{$\begin{array}{l}\text { Odd's } \\
1.3\end{array}$} & \multirow{2}{*}{$\frac{95 \% \mathrm{Cl}}{1.6-15.8}$} \\
\hline & Median & Latency (ms) & & & & \\
\hline & & Amplitude $(\mu \mathrm{V})$ & $-0.32^{* *}$ & 0.007 & 0.7 & $-0.1-0.0$ \\
\hline & & Conduction velocity $(\mathrm{m} / \mathrm{s})$ & 0.13 & 0.281 & 1.3 & $0.04-0.4$ \\
\hline & ulnar & Latency (ms) & $0.29^{*}$ & 0.013 & 1.6 & $7.1-25.6$ \\
\hline & & Amplitude $(\mu \mathrm{V})$ & $-0.28^{*}$ & 0.018 & 0.8 & $-0.1-0.01$ \\
\hline & & Conduction velocity $(\mathrm{m} / \mathrm{s})$ & 0.05 & 0.635 & 1.4 & $0.1-0.8$ \\
\hline
\end{tabular}

There was significant positive link between height and the latency of ulnar sensory nerve $(r=0.29$, $\mathrm{p}=0.01$, and odd's ratio was 1.6) as shown in Figure 1.

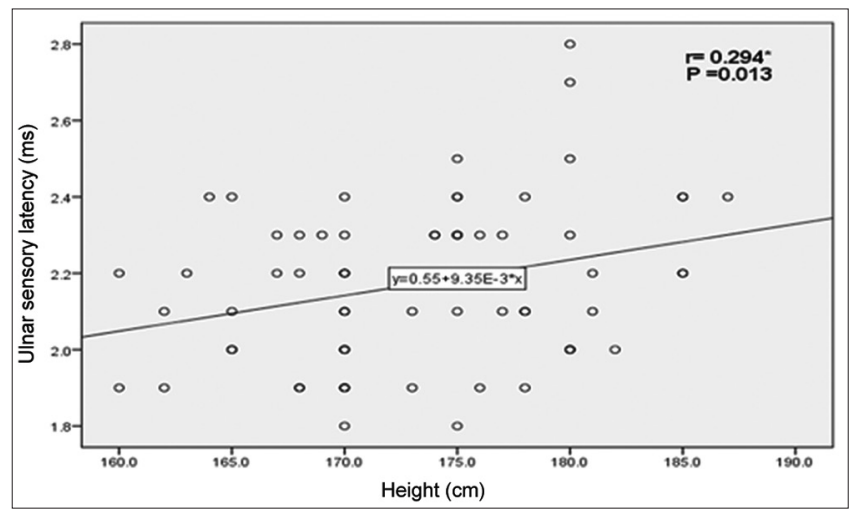

Figure 1: The association between height and ulnar sensory latency (ms) $(r=0.29, p=0.01$, and odd's ratio was 1.6)

At the same time, there was a significant negative power of height on median and ulnar sensory amplitude $(r=-0.32, p=0.007$ and $r=-0.28, p=0.018$, respectively) as it is clear in Figures 2 and 3 , respectively.



Figure 2: The correlation of height with median sensory amplitude $(\mu V)(r=-0.32$ and $p=0.007)$ 


\section{Discussion}

This study is mapped to evaluate the outcome of height on median and ulnar sensory and motor conduction parameters in healthy male subjects, there was a significant negative association among height and the sensory amplitude (SNAP) of median and ulnar nerves, meaning that whenever the height increases, the sensory amplitude will decrease and this consists with many studies like the studies of Kokotis and his coworkers [7],

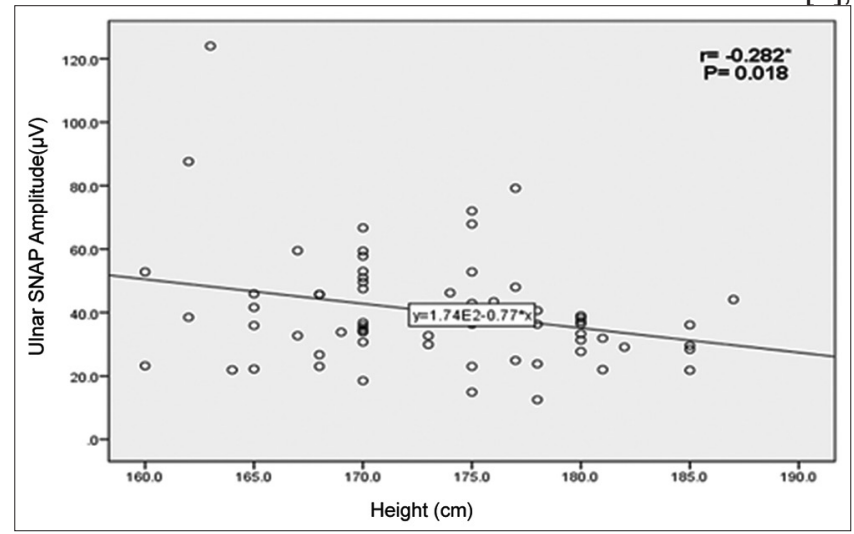

Figure 3: The correlation of height with ulnar sensory amplitude $(\mu \mathrm{V})$ $(r=-0.28$ and $p=0.018)$

Sulaxane and his coworkers [8] and Desai [9], the explanation for this is probably because the sensory fibers have diameter that is small distally and then increased proximally. Another important finding in this study was the positive association between the height and the ulnar sensory latency with odds ratio of 1.6. Desai and his assistances [9] also reach to this finding; sensibly, the conduction distance is increased with increased length resulting in increased latency. There was no association between height and conduction velocity in this study and this result similar to the results of many other researchers such as Awang et al. [7], Sulaxane et al. [10], and Bennal et al. [11] since when the nerve gets taller, this will results in tapering in nerves meaning that the diameter of the nerve fiber becomes smaller despite the increasing in myelin sheath distally. In a nice animal experiment on mature rabbit, the workers found that the diameter of the peripheral nerve was half that of ventral spinal nerve origin [12]. Mondelli $\mathrm{M}$ and his coworker [13] report a negative association of height with sensory and motor conduction velocity of median and ulnar nerves [13] while Huang et al. found a sensible correlation only with median nerve sensory conduction velocity [14].

\section{Conclusion}

The consequence of height on median and ulnar nerve conduction parameters (motor and sensory) is crucial for interpretation the data and later on the diagnosis of the diseases.

\section{References}

1. Preston DC, Shapiro BE. Basic nerve conduction studies. In: Electromyography and Neuromuscular Disorders. Boston: Butterworth-Heinemann; 2013. p. 778.

2. Aminoff MJ. Clinical electromyography. In: Electrodiagnosis in Clinical Neurology. $4^{\text {th }}$ ed. New York: Churchill Livingstone; 2010. p. 214-46.

3. Jagga M, Lehri A, Verma SK. Effect of aging and anthropometric measurements on nerve conduction properties a review. J Exerc Sci Physiother. 2011;7(1):1-10.

4. Bhorania S, Ichaporia RB. Effect of limb dominance on motor nerve conduction. Indian J Physiol Pharmacol. 2009;53(3):279-82. PMid:20329377

5. Saeed S, Akram M. Impact of anthropometric measures on surely nerve conduction in healthy subjects. J Ayub Med Coll Abbottabad. 2008;20(4):112-4. PMid:19999220

6. Singh M, Gupta S, Singh KD, Kumar A. Normative data for median nerve conduction in healthy young adults from Punjab, India. J Neurosci Rural Pract. 2017;8(Suppl 1):S83-8. https:// doi.org/10.4103/jnrp.jnrp_94_17

PMid:28936077

7. Sulaxane YD, Bhavasar PR. Impact of height on sensory nerve conductio. Natl J Physiol Pharm Pharmacol. 2017;7(8):851-4 https://doi.org/10.5455/njppp.2017.7.0410317042017

8. Kokotis P, Mandellos D, Papagianni A, Karandreas N. Nomogram for determining lower limit of the sural response. Clin Neurophysiol. 2010;121(4):561-3. https://doi.org/10.1016/j.clinph.2009.11.079 PMid:20097608

9. Desai B, Gokhale A, Gandhi H, Mehta HB, Shah CJ. Effect of sensory nerve conduction studies of median and ulnar nerve: Height and body mass index. Natl J Physiol Pharm Pharmacol. 2021;11(3):331-6. https://doi.org/10.5455/ njppp.2021.11.01027202126012021

10. Awang MF, Jafri MA, Mohd RA, Tharakan J, Prasad A, Husin ZA et al. Nerve conduction study among healthy Malays. The influence of age, height and body mass index on median, ulnar, common peroneal and sural nerves. Malaysian J Med Sci. 2006;13(2):19-23. PMid:22589600

11. Bennal AS, Pattar MY, Taklikar RH. Effect of height and BMI on nerve conduction velocity. Indian J Clin Anat Physiol. 2015;2(4):231-4.

12. Gierthmuehlen M, Freiman TM, Haastert-Talini K, Mueller A Kaminsky J, Stieglitz T, et al. Computational tissue volume reconstruction of a peripheral nerve using high-resolution lightmicroscopy and reconstruct. PLoS One. 2013;13;8(6):e66191. https://doi.org/10.1371/journal.pone.0066191 PMid:23785485

13. Mondelli M, Vinciguerra C, Aretini A, Ginanneschi F. The effects of anthropometric and demographic factors on conduction parameters of the ulnar nerve: Multivariate analysis. Neurosci Lett. 2020;734:135107. https://doi.org/10.1016/j.neulet.2020.135107 PMid:32485286

14. Huang CR, Chang WN, Chang HW, Tsai NW, Lu CH. Effects of age, gender, height, and weight on late responses and nerve conduction study parameters. Acta Neurol Taiwan. 2009;18(4):242-9.

PMid:20329591 